\title{
FELA, DE CARLOS MOORE: NARRATIVAS DE UM ABIKU
}

RESUMO: Este artigo busca fazer um estudo do livro Fela. Esta vida Puta, assinado pelo etnólogo cubano Carlos Moore tendo como foco as estratégias de elaboração de uma narrativa biográfica composta por várias vozes. A obra tem como base uma série de entrevistas realizadas por Moore entre 1981 e 1982, com Fela Kuti e outras figuras-chave de sua vida as quais complementam ou questionam a voz do biografado. Nota-se que a montagem do texto toma alguns temas típicos das narrativas biográficas (predestinação, acontecimento traumático e epifanias) como princípio organizador das entrevistas. Além disso, a obra conta com a presença intrigante de Afa Ojo, personagem espiritual da falecida mãe de Fela. Artifício dramático, a narrativa de Afa Ojo oper uma ressignificação da vida do filho sob o signo do Abiku, espírito da mitologia ioruba, nascido duas vezes na mesma família. Articuladas, essas narrativas constroem uma imagem multifacetada de Fela, intimamente relacionada à sua visão pan-africanista da vida e da arte.

PALAVRAS-CHAVE: Fela Kuti; Carlos Moore; narrativas biográficas.
ABSTRACT: This article intends to study the book Fela. Esta vida Puta (Fela. This bitch of a life), written by the Cuban ethnologist Carlos Moore. It focuses on the strategies used in order to build a biographic narrative which has been composed by a variety of voices. The work is based on a series of interviews taken by Carlos Moore between 1981 and 1982 with Fela Kuti and other key figures in his life whose voice complements or questions that of the biographic subject. It is noticed that the text is assembled through the use of some typical themes in the biographic narratives (predestination, tragic event and epiphany). Besides, there is Afa Ojo, the intriguing spiritual character of Fela's deceased mother. As a dramatic artifice, Afa Ojo redefines the meanings in he son's life under the sign of Abiku, a mythological Yoruba spirit who is born twice into the same family. Combined, (1) which is closely related to his pan-Africanist views of life and arts. KEYWORDS: Fela Kuti; Carlos Moore; biographic narratives 
1. Das vinte e sete esposas com quem Fela se casara, fevereiro de 1978 , catorze ainda viviam em sua casa, á́m Remi, primasa, com quem ele se casara em 1961.
"In vain your bangles cast Charmed circles at my feet I am Abiku, calling for the first And repeated time"

Wole Soyinka, "Abiku"

"I'm finished, mother"

Fela Kuti, em “Unknow Soldier".

No ano de 1981, o etnólogo cubano Carlos Moore, então radicado em Paris, onde trabalhava como jornalista, recebe um telefonema originado de Lagos. Tratava-se da mensagem de um amigo, o músico e ativista Fela Kuti, que lhe convocava, por meio de um assessor, a viajar imediatamente para a capital da Nigéria. Naquele momento, Fela confiava Moore a tarefa de compor sua biografia, a qual - Moore saberia mais tarde - viria a ser considerada a primeira a tratar da vida de um artista africano.

Moore viaja, então, à casa de Fela, na Kalakuta Republic (República de Kalakuta), nome dado pelo artista à comunidade que abrigava os membros de sua família e de sua banda, além de alguns agregados simpáticos às causas políticas por ele defendidas. A viagem de Moore lhe permitiu realizar uma série de entrevistas com Fela, com seu assessor e amigo J. K. Braihma e com cada uma das quinze esposas que moravam na República de Kalakuta à época ${ }^{1}$, resultando na biografia polifônica Fela. Esta vida puta, publicada no ano de $1982 \mathrm{em}$ Londres e Paris e finalmente traduzida para publicação no Brasil, em 2011.

A biografia interessa por algumas características especiais, das quais gostaríamos de destacar duas, que irão nortear as reflexões deste trabalho. Em primeiro lugar, por sua estrutura heterogênea, sobretudo no que concerne às vozes narrativas. Embora quem assine a obra seja Carlos Moore, a narração biográfica dos 25 capítulos é conduzida, de maneira alternada, pela voz de Fela Kuti (na primeira pessoa, em 18 capítulos) e pela voz das pessoas entrevistadas (em 5 capítulos, um dos quais se desmembra nas quinze entrevistas com as esposas de Fela).

A conta dos 25 capítulos se fecha, ainda, com a abertura e o encerramento da obra, impressos em páginas negras sob o título de "Afa Ojo - Aquela que comanda a chuva", nos quais a o espírito da falecida mãe de Fela toma palavra. Esses dois capítulos delimitadores das fronteiras da narrativa biográfica nos fornecem a segunda característica intrigante: a presença de uma voz espiritual, imersa no imaginário mítico iorubá. Tal voz é identificada a uma personagem da biografia, Funmilayo (mãe de Fela), de quem a vida, a morte e alguns de seus retornos ao mundo dos vivos são resumidos por Fela Kuti no decorrer da narrativa. 
2. Alguns exemplos: “Minha mãe conseguiu derrubar esse pseudorei, o Alake. Como é que ela Foi engenhoso..." (MOORE, 2011, p.52); “Como eu me envolvi com maconha? Você pode não acreditar em mim, mas foi uma garota que me iniciou no fumo... (p.82); "Adivinha o que ele fez... aquele sujeito? $O$ julgamento tinha sido marcado pro dia 27 de novembro de 1974, né?..." (p.144); “Ela nunca se recuperou dos ferimentos e do choque que ela sofreu durante $\mathrm{o}$ ataque à Kalakuta, sabe?" (p.260). Todos os destaques são nossos.

3. Tais instrumentos de legitimação da autenticidade da presença do Fela Kuti "real" no texto aproximariam o livro de uma da autobiografia sobretudo da autobiografia, sobretudo se considerarias so famosa (e cojeune dessênero como: Lnarrativa retrospectiva como: "narrativa retrospectiva em prosa que uma pessoa real faz de sua própria existencia, quando em particular a históri em particular a historia de sua personalidade" (LEJEUNE, 2008, p.14). Embora a heterogeneidade da obra impeça sua mera classificaçăo nesse gênero, $e$ interessante perceber como uma biografia contemporânea, produzida a partir de fontes orais na Nigeria, vale-se de artificios narrativos semelhantes aos dos gêneros tradicionais da literatura francesa desde Rousseau.
Diante dessas características, parece possível dizer que a predominância da voz de Fela Kuti faz com que a obra flerte com os gêneros autobiográficos. Sobretudo quando sabemos, por meio dos comentários de Moore que precedem o texto, que a presença da voz do músico em primeira pessoa corresponde às entrevistas de 1981, em Lagos. Ta asserção do biógrafo busca legitimar a autenticidade da biografia como presença do biografado diante do leitor, assim como algumas marcas textuais: o aproveitamento e ênfase da oralidade na redação dos capítulos, o uso de fotos de arquivo na abertura e no decorrer da biografia, relacionados aos eventos narrados, e a sugestão de uma voz interlocutor implícita - a do entrevistador. Essa voz se faz notar por meio de questionamentos que direcionam a progressão temática e por meio de marcadores discursivos de interação que interrogam o entrevistador (né?; sabe?, saca?) ${ }^{2}$. São marcas que emprestam autenticidade ao texto diante do leitor, apresentando-lhe uma proposta de leitura da narração do artista nigeriano como relato autobiográfico ${ }^{3}$.

Trata-se, contudo, de um relato autobiográfico impuro. A voz do entrevistador, implícita no discurso e explicitada pelo para-texto ("Nota do autor", "Introdução" e "Epílogo", assinados por Moore), media os rumos e o ritmo da narrativa. Dessa forma, a vida de Fela Kuti é vista, a princípio, por três olhares: o do entrevistador (Moore), o do entrevistado (Fela) e o do leitor. E essa tripla visada logo se multiplica ad infinitum quando, no decorrer do livro, são apresentadas as entrevistas com personagens que figuram no relato de Fela, com a voz de Moore explicitada no texto. Desse modo, o relato autobiográfico ganha traços de biografia, gênero impuro por excelência (DOSSE, 2009, p.55-122), já que depende das tensões constantes entre as visões que cada um dos sujeitos da narrativa tem do passado vivido e a imaginação criadora de Carlos Moore, responsável por selecionar e combinar o tecido de relatos colhidos ${ }^{4}$.

Essa reflexão fundamenta a proposição deste trabalho, a saber, a de que a multiplicidade de vozes mediadas por Moore modifica a narrativa biográfica de tal maneira que o livro se constitui como reunião de relatos biográficos diversos, fragmentados e tensionados entre si e reunidos em torno de alguns temas.

\section{AFA OJO, ESPÍRITO BIÓGRAFO - PARTE I}

Como afirmamos, "Afa Ojo - aquela que comanda a chuva" é o título tanto do primeiro, como do último capítulo da obra. Mas, como poderia um espírito narrar uma biografia não-ficcional? Vejamos o que diz Moore sobre essa personagem-narradora, em nota, no epílogo do livro:

O monólogo Afa Ojo, composto por mim para as edições originais deste livro - em inglês e francês (1982) -, foi escrito
4. Para François Dosse, a biografia é um gênero híbrido que "se situa em tensão constante entre a vontade de reproduzir um vivido real passado, segundo as regras da mimesis, e o polo imaginativo do biógrafo, que deve refazer um universo perdido segundo sua intuição e talento criador" (DOSSE, 2009, p.55). Na biografia em questão, essa impureza é amplificada pela multiplicação de sujeitos que ocupam a posição de "biógrafos" da vida de Fela: Moore, cada um dos entrevistados e o próprio biografado. Se podemos dizer que Moore é o autor de Fela. Esta vida puta, é somente por ter sido ele o responsável pela seleção e combinação dos relatos para a composição do texto final, atos que, na visão de Wolfgang Iser (2002, p.957-984), fazem com que o texto se apresente para o leitor "como se" ele estivesse diante do mundo empírico. Moore torna-se biógrafo na medida em que reúne os relatos e os apresenta para o leitor como se ele estivesse diante dos entrevistados.
EM TESE
BELO HORIZONTE
v. 20
N. 3
SET.-DEz. 2014 BICALHO. Fela, de Carlos Moore: narrativas de um Abiku
P. 25-35 
5. “Esta carta é para deixar absolutamente claro que toda é não fictícia Carlos tem uma érie de entrevistas gravadas para comprovar a quatquer para comprovar, a qualquer carta" (trad nossa). A tradução da " (trad. nossa). A tradução ta carta "ontida no livro preferiu "ñ̃o são falsas". Retraduzimo paro săo falsas". Retraduzimos estatuto de ficção do monólogo espiritual. por minha ex-esposa, Shawna, ela própria uma escritora. Ela o escreveu a meu pedido, mas seguindo sua própria inspiração literária. Concebido como um artifício meramente dramático para apresentar a explicação de Fela de um milagroso "nascimento duplo", foi também uma resposta definitiva ao desejo declarado de Fela de acabar com sua própria vida e "deixar este mundo". (MOORE, 2011, p. 306)

A voz espiritual é trazida para o texto como um artifício dramático, produzido por Shawna Davis a partir da própria narrativa de Fela (multiplicando, mais uma vez, o espelhamento de vozes). No entanto, o estatuto de ficcionalidade do monólogo, desnudado pela declaração de Moore, não é estável. Um outro dado para-textual, por exemplo, questiona-o. Trata-se da reprodução impressa nas primeiras páginas do livro de uma carta de autorização da publicação da biografia, assinada por Fela Anikulapo-Kuti e enviada aos editores franceses, em dezembro de 1981. Na carta, Fela descreve os procedimentos biográficos de Moore, diz estar de acordo com eles e afirma, após ter lido o livro:

This letter is to make it abundantly clear that every information inside the book is not ficticious. Carlos has a series of recorded interviews to prove his case any day - this letter not withstanding. (KUTI apud MOORE, 2011, p. 10. Grifos nossos. $)^{5}$
Assim, a autoridade do biografado é apresentada na edição, sob licença do biógrafo, de forma tal que empresta à voz de Afa Ojo um caráter não fictício. Ademais, as páginas negras que abrem a narrativa biográfica cuidam de apresentar uma versão do nascimento de Fela Kuti em consonância com a narrativa do próprio biografado sobre esse momento decisivo, apresentada no capítulo seguinte. Afa Ojo, lembrando-se da própria vida, fala do nascimento de seu segundo filho:

em 1935, um segundo filho nasceu. Dessa vez, deixamos que um missionário alemão, que vivia em Abeokuta, escolhesse o nome desta criança e se tornasse seu padrinho. Ele deu o nome de Hildegart. Nenhum de nós sabia o significado desse nome. E pagaríamos caro por nosso erro. Ó, Olodumaré! Perdoai-nos! Duas semanas após seu nascimento, Hildegart faleceu subitamente. (...)

Em 1938 nasceu aquele a quem chamaríamos de Fela. Esta criança não poderia ser senão "aquele que emana grandeza" (MOORE, 2011, p.31)

Fela, no segundo capítulo da biografia, intitulado "Abiku - Aquele que veio ao mundo duas vezes”, conta a história de forma semelhante. Também atribui a causa da morte do bebê ao nome europeu, escolhido "pra agradar a um desses brancos aí", logo na África, onde "os nomes são levados tão a sério" (p.36). A nuance é que, na narrativa de Fela, o bebê 
6. Remetemos mais uma vez, aqui, a Lejeune (2008), que associa a ascensão dos gêneros autobiográficos à noção de individualidade, sobretudo a partir das Confissóes de Rousseau, marco histórico que embasa sua teoria. Ainda outros autores, como Peter Burke, associam a ascensão da biografia moderna à construção da subjetividade e à "noção de que a personalidade passa por um processo de desenvolvimento" (BURKE, 1997, p.96).

7. "De acordo com o costume dos iorubás, um Abiku é uma criança que morre e renasce várias vezes na mesma família; dessa forma o tempo de vida de um Abiku é caracteristicamente muito curto, de fato. Devido à natureza efêmera de sua vida, um Abiku completa vários ciclos de vida consecutivos com uma mãe" (trad. nossa). era ele próprio (“a primeira vez que nasci foi em 1935”, p.36) e sua morte prematura marca a rejeição do eu-nascente de vir ao mundo sob um nome europeu.

O renascimento sob novo nome, um nome africano, é determinante para a biografia. A ideia de que o biografado, recém-nascido, recusa o nome europeu pode soar inverídica para o leitor cético, mas está de acordo com a mitologia iorubá. Nesse pensamento mítico, articulado no discurso do narrador Fela, a recusa é fruto de uma consciência espiritual, distinta da ideia de formação de consciência individual da cultura ocidental, fundamento da noção tradiciona das (auto)biografias modernas ${ }^{6}$. Como o título do capítulo sugere e o restante do livro cuidará de comprovar, trata-se de uma escolha feita entre a vida e a morte, por uma entidade espiritual conhecida pelos povos iorubás como Abiku. Segundo Timothy Mobolade,

According to the custom of the Yorubas, an Abiku is any child who dies and is reborn several times into the same family; hence, the life-span of an Abiku is characteristically very short, indeed.

Owing to the ephemeral nature of its life, an Abiku completes several consecutive life-cycles with one mother (MOBOLADE, 1973, p.62) 7 .
Ainda de acordo com Mobolade, a nomeação é frequentemente muito importante no caso de famílias que geram bebês Abikus, sendo que muitas vezes nomes são dados à nova criança cujo sentido denota uma tentativa de persuadi-la a permanecer viva.

A ideia, veiculada por Fela, de que ele é um $A b i k u$, alguém que nasce duas vezes, não apenas legitima a verdade biográfica do discurso de $A f a O j o$, como transforma sua narrativa no que chamaremos provisoriamente de "relato autobiográfico espiritual”. Trata-se de uma noção complexa e aparentemente contraditória: como narrar a vida de um espírito, um ser que se encontra entre a vida e a morte? Não se trataria mais, portanto, de uma biografia, mas de um texto que flerta com a noção de ficção biográfica, categoria híbrida entre a biografia e o romance, capaz de testemunhar os limites da noção positivista de indivíduo (MONLUÇON, SALHA, 2007).

No entanto, outras vozes, mais individualizadas, compõem a narrativa de Fela. Embora não se oponham ao relato do Abiku, elas restituem para o leitor a possibilidade de ler-se a obra por um viés biográfico.

\section{PREDESTINAÇÃO, ACONTECIMENTO TRAUMÁTICO E}

\section{EPIFANIAS}

Quanto a esse viés biográfico, é necessário sublinhar as condições de produção das entrevistas que servem de base 
8. A entrevista com Sandra, amiga e ex-amante de Fela Kuti, foi possivelmente realizada em outro momento que não o da viagem, já que morava nos Estados Unidos. De todo modo, trata-se de uma distância temporal pouco significativa, já que o livro foi publicado apenas um ano depois, em 1982

9. A breve e conhecida elaboração do conceito de "biografema" por Sade Fourier e Loyola, Sade, Fourier Loyola, segundo am fragmento ou inflexã como uida em dispersão, tocar momer corpos diversos (BARTHES, 2005, p.XVII), nos provos a pens, potencial que uma a pens potencial que uma obra de viés primordialmente por, composta possui de produzir biografemas. possui de produzir biografemas. Como aitma Leonor Arfuch, a entrevista, forma dialógica, poss a caracteristica de investir os gêneros biográficos de sentidos comuns, que ultrapassam a subetre dade do entrevistado. Dentre esses serido a vida pode ser tomada como o desdobramento do personagem que se narra diante desse outro, o entrevistado - cujo olhar é determinante -, colocando em jogo diversos 'biografemas' ou movimentos estereotípicos (ARFUCH, 2010, p.159). para a composição do livro. Todas elas foram realizadas por Moore durante a viagem a Lagos, em $1981^{\circ}$. Naquele momento, Moore explicita em seu epílogo, Fela "se encontrava em uma crise existencial" (MOORE, 2011, p.305). Abalado com a morte recente da mãe e esgotado pelos anos de luta contra o regime ditatorial nigeriano, o músico passava por uma verdadeira guinada espiritual, a que Carlos Moore chamará de "segunda epifania" (p.307). O epílogo não apenas esclarece o contexto de concepção do livro, como nos ajuda a perceber o gesto autoral de Moore ao compor a biografia a eleição de alguns temas biográficos presentes no relato de Fela para estabelecer um princípio de organização do relato. São eles a predestinação, o acontecimento traumático e as epifanias. Esses temas, que remontam movimentos típicos das narrativas de vida, organizam os elementos da vida de Fela que emergem de maneira relativamente espontânea na dinâmica da entrevista. Por meio deles, Moore convoca outras vozes para dialogarem com a do biografado e a sua própria, ampliando as possibilidades de leitura dos fragmentos biográficos. Relacionados a esses temas maiores e vistos sob os múltiplos olhares dos entrevistados, alguns desses fragmentos podem, inclusive, vir a tornar-se "biografemas" que ultrapassam os limites da vida de Fela para tocar outras vidas em dispersão no livro? .

Passamos a comentar a dinâmica de construção dos temas:
- Predestinação $0^{10}:$ A ideia da predestinação de Fela é introduzida pela narrativa de abertura da obra por Afa Ojo. O espírito de Funmilayo narra como esta, após o nascimento de Fela, resolve consultar um babalaô ${ }^{11}$, já que enxergava "insolência, teimosia, imprudência desmedida, arrogância e lascívia" (MOORE, 2011, p.31) nos olhos da criança. A profecia do oráculo do Ifá, então anunciada, resumirá, de antemão, os acontecimentos da vida de Fela: "A criança será teimosa, impetuosa, incontrolável...”, frase que antecipa a obstinação do artista na luta contra a injustiça promovida pelos governos ditatoriais da Nigéria e outros países da África pós-colonial, mesmo tendo sido preso mais de cem vezes; "Seu caminho, repleto de armadilhas... tumulto e violência...", predição confirmada pelas muitas vezes em que foi preso e espancado pelas autoridades nigerianas, frequentemente sem qualquer fundamento legal; "Suas esposas, numerosas...", mais precisamente, vinte e oito; "Ele viverá na pobreza, ao lado de pedintes e ladrões”, a República de Kalakuta, onde Fela viveu até o fim da vida, ficava na periferia de Lagos, em um dos bairros mais pobres e violentos da cidade; "Seus amigos serão exilados... e ele será rotulado fora-da-lei”, vaticínio confirmado pelo grande número de amigos perseguidos e presos pelo regime, além da veiculação da imagem de Fela pela mídia nigeriana como inimigo do Estado.
10. A predestinação é um tema clássico dos gêneros biográficos, presente na antiguidade $\mathrm{e}$ bastante convencional em biografias renascentistas (ct. BURKE, 1997, p.88-90), além de ser destacado pela teórica argentina Leonor Arfuch como motivo estereotípico despertado por biografemas (articulado à ideia de vocação, no caso de artistas) bastante comum em entrevistas contemporâneas (ARFUCH, 2010, p.201-203).

11. Na cultura iorubá, assim como em algumas religiões afro-brasileiras, o babalaô é sacerdote que se comunica com os orixás, geralmente pa cerrenos das vidas humanas.

$\begin{array}{lllll}\text { EM TESE } & \text { BELO HORIZONTE } & \text { v. } 20 & \text { N. } 3 \quad \text { Set.-Dez. } 2014 & \text { BICALHO. Fela, de Carlos Moore: narrativas de um Abiku }\end{array}$


A voz do espírito da mãe, composta pela pena de uma outra mulher, Shawna Davis, funciona, portanto, como fundamento do relato autobiográfico espiritual de Fela/ Abiku.

- A primeira epifania: A primeira epifania de Fela ocorre durante uma viagem duradoura para os Estados Unidos, em 1969. Nessa época, o músico fazia parte de uma banda chamada Koola Lobitos, que tocava músicas sobre assuntos pouco politizados, no estilo musical Highlife, originado em Gana, mas tocado com instrumentos ocidentais. Tratava-se, portanto de uma turnê musical da Koola Lobitos para o continente americano, mas que acaba por se tornar uma viagem de reconhecimento. Essa virada se dá quando Fela conhece Sandra, uma cantora afro-americana e militante do movimento Black Power, por quem se apaixona profundamente. O encontro com Sandra é narrado por ele e, logo em seguida, pela própria cantora, em entrevista, tendo como foco um assunto: a construção de uma negritude pan-africana. Foi a partir da leitura da Autobiografia de Malcom X, indicada por Sandra, que Fela tomou consciência de sua identidade política:

Eu tava agarrado no livro que ela tinha me dado pra ler: A auto biogra fia de Malcom X. (...) Ele falava sobre a história da África, sobre os brancos... Ahhhhh! Eu nunca tinha lido um livro como aquele na minha vida! (...) Dá pra imaginar como isso me fascinou? Ahhhh! Pensei: “Porra! Taí um HOMEM!” Eu queria ser como Malcom X! Caralho! Eu queria ser Malcom
$\mathrm{X}$, saca? Fiquei muito triste que esse cara tenha sido morto! E, aí... e aí, cara, tudo sobre a África começou a voltar em mim. (MOORE, 2011, p.94, grifos do autor)

A consciência política sobre a África é percebida por Fela como um retorno, um despertar para algo que já estava dentro de si, por meio de uma leitura autobiográfica. Também para Sandra, foi necessário um "retorno" à África, anos depois, para que percebesse que havia "africanizado" Fela:

Então, você não sabia que o Fela não estava lá? Que era você que o estava "africanizando"? Quando foi que você descobriu?

Eu não sabia disso na época. Eu estava envolvida com Fela. Eu imaginava que ele já estivesse lá. (...) Só fui descobrir em 1976, quando voltei à África para fazer o álbum "De cabeça para baixo" (Upside Down). Percebi, então, que tudo estava de cabeça para baixo, mesmo. (MOORE, 2011, p.106)

Pelo artifício da entrevista, a epifania de Fela é posta em diálogo com a de Sandra, que, após viajar para a África, retorna com uma consciência amadurecida de sua negritude. Conjugadas, as duas revelações colaboram para a construção de uma consciência pan-africana por meio de uma paixão que ao longo dos anos tornou-se amizade e, de acordo com Sandra, uma irmandade espiritual (p.119). 
12. A canção em questão é My lady's frustration. Fela se inspirou em Sandra, ao vê-la frustrada com a situação de pobreza e precariedade em que ele e sua banda se encontravam em solo americano, a despeito do talento musical.
- Acontecimento traumático - a invasão de Kalakuta: a primeira epifania faz com que, nos anos que se seguem ao retorno dos Estados Unidos, Fela experimente uma crescente politização de seus atos e de sua música. Segundo Fela, Sandra fora a responsável pela primeira vez em que ele tocou uma música realmente africana ${ }^{12}$. Daí pra frente, ele utilizaria o Afrobeat - estilo musical por ele criado na busca de reaproximar-se das raízes musicais africanas - para protestar contra as injustiças frequentes na vida do povo nigeriano. Foi nessa época que Fela instituiu em sua casa a Kalakuta Republic e nela instalou uma boate (intitulada Shrine, Santuário), onde performatizava suas músicas que, com frequência, atacavam diretamente o governo da Nigéria. O conteúdo das músicas, bem como a afronta representada por uma comunidade libertária em um governo ditatorial, liderada por uma figura cada vez mais incômoda para o regime, fizeram com que, em 18 de fevereiro de 1977, a casa de Fela fosse invadida e incendiada por cerca de mil soldados, que espancaram brutalmente os moradores, incluindo Fela, suas mulheres e sua mãe. Os soldados foram especialmente cruéis com as mulheres, provavelmente pelo incômodo que geravam na sociedade nigeriana por terem abandonado as famílias para viver uma vida mais livre em Kalakuta. Várias delas são estupradas ou sofrem cortes com garrafas em todo corpo e em suas vaginas.
O relato da brutalidade dos policiais, bem como a sugestão do caráter libertário e subversivo da união deliberada dessas mulheres com Fela, são trazidos para a cena biográfica através das quinze entrevistas realizadas com as esposas. Nas entrevistas, temos contato não apenas com a voz dessas mulheres, que ocupavam o posto de "Rainhas" dentro da República de Kalakuta, mas também com a profundidade do trauma em suas vidas e em seus corpos, através das lacunas e silêncios que entrecortam seus relatos.

Além das esposas, a mãe de Fela sofre conseqüências indeléveis da violência policial. Jogada pela janela da casa pelos soldados durante a invasão, é internada em um hospital e, algum tempo depois, vem a falecer. Sua morte não apenas gera um sentimento de revolta em Fela, que chega a levar o caixão da mãe até a porta do palácio do general Obasanjo clamando por justiça, como também acaba por despertar a segunda epifania.

- Segunda epifania: ao narrar o funeral de sua mãe, em um dia de sol muito quente, Fela conta que uma chuva forte começou cair sobre a cabeça das aproximadamente cinquenta mil pessoas que carregavam o caixão ${ }^{13}$ :

Chover é normal, é verdade. Mas o que aconteceu naquele dia não foi normal, cara. Eu sabia que minha mãe ia usar a chuva
13. O grande número de pessoas acompanhando o funeral pexplica nao apenas pela copúm tamberm pela de Funmilayo, que havia sido uma importante tivistá dos direitos das mulheres na Nigéria. Funmilayo chegara a conhecer Mao Tsé Tung e a liderar um grupo de mulheres que derrubou o admnistrador $d$ cidade de Abeokuta no fim dos anos quarenta. 
pra se comunicar comigo de algum jeito. Desde então, a chuva se tornou um sinal na minha vida (MOORE, 2011, p.264).

Em outros momentos importantes, como no dia em que Fela e os moradores de Kalakuta carregam o caixão até os portões do palácio de Obasanjo ou quando Fela é preso durante uma turnê na Itália, chovia forte também. Fela interpreta esses sinais como formas da mãe de se comunicar com ele. Mas é apenas em 1981 que a segunda epifania ocorre. Femi Kuti, um de seus filhos, começa a sofrer com uma febre de Malária resistente a remédios e ervas medicinais. Durante a febre, Femi vê a imagem de Funmilayo em seu quarto, onde estava reunido com amigos. A visão dá início a uma série de incorporações espirituais e a uma sequência de rituais em Kalakuta, com a duração de dez dias, nos quais Fela é orientado espiritualmente por várias entidades que se comunicam com ele. A epifania se completa quando Fela incorpora um espírito e, uma de suas esposas, Adejonwo incorpora o espírito da mãe: "O espírito ficou em meu corpo umas duas horas. O espírito me levou adiante e me trouxe de volta. Aquele ritual me levou para o Egito e pra Ifé" (p.272) Fela tem uma série de revelações, dentre as quais a certeza de que a República de Kalakuta era o verdadeiro centro do mundo e que o Egito fora a origem da humanidade (por isso, Fela mudaria nome de sua banda, de Africa 70 para Egypt 80).

Naturalmente, caía um grande temporal quando os rituais se iniciaram.

\section{AFA OJO, ESPÍRITO BIÓGRAFO - PARTE II}

É nesse momento de revelação espiritual que Fela concede seu relato autobiográfico para Moore. Ao final da biografia, Fela revela a segunda epifania como um segredo, uma confissão ("Eu vou te contar uma parada pesada que eu nunca contei pra ninguém!" p.268), e afirma: “A coisa toda parece que está se encaixando nos últimos dez anos” (p. 272), tempo que corresponde, aproximadamente, ao período entre as duas epifanias. O fato de Fela ter escolhido justamente esse momento de revelação espiritual para dar seu relato sugere um ponto fulcral da vida do biografado, em que este parece perceber a própria existência sob a unidade de uma revelação:

Quem sou eu? Agora eu sei. Me foi revelado num transe. O espírito me contou quem eu era. E pra que eu vim. Mas isso não vou dizer pra ninguém. Nunca! Talvez, algum dia, eu tenha que revelar. Talvez. Tudo que posso dizer agora é: eu sei exatamente quem eu sou e o que vim fazer aqui. (MOORE, 2011, p.278)

A crença na vida como missão vai ao encontro do tema da predestinação. Mas é apenas após o fim da narrativa de Fela, quando retorna à cena o espírito da mãe para revelar o 
14. Na mitologia iorubá, orixá superior, responsável pela criação do universo. segredo da vida do filho, que o ciclo se completa. A unidade biográfica, forjada pela progressão cronológica, dá lugar, então, à compreensão da vida como passagem, momento de uma temporalidade cíclica cujo sentido só pode ser atribuído de um ponto de vista da eternidade. E é desse lugar imaginado que fala Afa Ojo, dirigindo-se ao filho: "Dê ouvidos, pois, à voz do tempo eterno (...) Saiba que todo Homem nasce com uma missão, que ele cumpre ou abandona. E a razão para isso é o que vou revelar agora" (p.291). O espírito narra então, um mito de criação da humanidade, cuja função seria a de combater um espírito, o Ibi (o Mal), que fora expulso do domínio dos orixás e passara a habitar a terra. Segundo o mito, todo ser humano, ao nascer, seria atravessado pelos 666 dardos de $I b i$, mas portaria também sete flechas protetoras, fornecidas por cada um dos sete principais orixás Alguns, porém, nascem com uma oitava flecha, fornecida por Olodumaré ${ }^{14}$, para que lembrem os seres humanos de sua razão de ser: trata-se do dom da criação. Fela seria um 7 +1 , assim como todos os Abiku.

A revelação une a epifania à predestinação, revestindo narrativa do Abiku de verdade biográfica. Se a profecia do babalaô, na primeira parte do monólogo de Afa Ojo, fundamenta e explica os acontecimentos narrados por Fela, a segunda parte entrelaça a biografia e, por outro lado, extrapola, ao propor o sentido de uma vida que se encontra ainda em devir.

Ao inscrever a voz de Afa Ojo, Carlos Moore e Shawna Davis buscaram contrapor a intenção declarada por Fela Kuti de praticar o suicídio, em um momento de crise. $\mathrm{O}$ trabalho do biógrafo, que busca dar sentido aos eventos do passado, já somado ao do entrevistador, que propõe "uma atualização da história, capaz de ressignificar o já conhecido" (ARFUCH, 2010, p.194), encontra, agora, o do ficcionista, que se fundamenta na crença da possibilidade de transformação do real. Não sabemos do impacto da biografia de Moore na vida de Fela Kuti, após sua publicação, e se teria influenciado o artista a não se suicidar - sua morte só viria a acontecer quinze anos depois, por complicações associadas ao vírus da AIDS De todo modo, acreditamos ser possível afirmar, em uma leitura condizente com a biografia de Moore, que, até seus últimos dias, Fela abraçou a missão que lhe fora confiada pelas palavras da mãe espiritual, utilizando a flecha da criação como arma de combate à opressão e às injustiças que assolavam o povo nigeriano.

\section{REFERÊNCIAS}

ARFUCH, Leonor. 0 espaço biográfico: dilemas da subjetividade contemporânea. Trad. Paloma Vidal. Rio de Janeiro: Ed. UERJ, 2010 
BARTHES, Roland. Prefácio. In: BARTHES, Roland. Sade, Fourier

Loyola. Trad. Mário Laranjeira. São Paulo: Martins Fontes, 2005.

BURKE, Peter. A invenção da biografia e o individualismo

renascentista. Trad. José Augusto Drummond. Estudos

Históricos, Rio de Janeiro, v. 10, n. 19, 1997, p.83-97.

DOSSE, François. A biografia, gênero impuro. In: DOSSE,

François. $\mathbf{O}$ desafio biográfico: escrever uma vida. Trad. Gilson

César Cardoso de Souza. São Paulo: Editora da USP, 2009, p.55122

ISER, Wolfgang. Atos de fingir ou o que é fictício no texto

ficcional. In.: LIMA, Luiz Costa (Org.). Teoria da literatura em

suas fontes. Vol. 2. 3 ed. Rio de Janeiro: Civilização Brasileira,

2002. p.955 a 984

LEJEUNE, Phillip. $\mathbf{O}$ pacto autobiográfico - de Rousseau à

Internet. Trad. Jovita Maria Gerheim Noronha e Maria Inês

Coimbra Guedes. Belo Horizonte: UFMG, 2008.

MOBOLADE, Timothy. The Concept of Abiku. African Arts, Los

Angeles, vol. 7, n. 1, Outono, 1973, p.61-63.

MOORE, Carlos. Fela. Esta vida puta. Trad. Bruno Madeira. Belo Horizonte: Nandyala: 2011 